\title{
Obsesivos días circulares de Gustavo Sainz: análisis de la situación narrativa ${ }^{1}$
}

\author{
INKE MŨLlER \\ Universität Hamburg
}

Preámbulo

Cuando en 1965 el joven escritor mexicano Gustavo Sainz (n. 1940) publica su primera novela, Gazapo, repite lo que pocos años antes (en 1958) había logrado Carlos Fuentes con La región más transparente: presenta una obra cuya construcción poetológica refleja una madurez literaria que no se hubiera esperado de un escritor que se inicia en el género. La novela se convierte en un rápido éxito de venta.

En 1969 aparece Obsesivos días circulares, la segunda novela de Sainz. Se trata de un texto que presenta muchas dificultades de lectura y no alcanza el éxito de Gazapo. Diez años después de la primera edición de Obsesivos días circulares el autor publica una segunda (1979), en la cual ciertos aspectos han sido elaborados con más énfasis. Además de ilustraciones y cambios en la disposición tipográfica, el libro incluye —en forma de epilogo- una interpretación del hispanista estadounidense David Decker. Según

${ }^{1}$ El presente estudio, reelaborado y traducido al español, forma parte de un trabajo con el cual la autora recibió el lítulo de Magistra Artium en la Universidad de Hamburgo, Alemania Federal. 
declaraciones de Sainz, las modificaciones del texto ya habian sido previstas para la primera edición; sin embargo, no pudieron ser realizadas por problemas de presupuesto en la editorial.

Gazapo y Obsesivos días circulares se distinguen también con respecto al plano del contenido. Mientras la primera novela se dedica al mundo de la adolescencia, aquel periodo transitorio entre la infancia y la edad adulta, Terencio, el protagonista de la segunda, ya ha superado esta fase de desarrollo desde hace tiempo. Con esta figura Sainz dibuja el carácter de un hombre abrumado por íntimas contradicciones entre rebelión y conformismo. Por un lado, Terencio reconoce el radicalismo artificial de su generación, su carencia de sinceridad, su superficialidad, la brutalidad y corruptibilidad de su jefe; pero, por otro, no está dispuesto a rebelarse abiertamente contra esta situación. Terencio es un ser indiferente, ama la comodidad y es incapaz de asumir responsabilidades o de tomar decisiones. En vez de descargar explícitamente su crítica, prefiere vivir y sufrir estas contradicciones.

\section{Presentación del marco teórico}

Cada texto literario puede ser descrito - dentro de un plantedmiento semítico- como componente de un proceso comunicativo, o bien, de un proceso de interacción, en el cual un hablante que tiene una determinada intención transmite un mensaje a un destinatario que posee una determinada expectativa. El mensaje es el texto literario, con los distintos planos que constituyen su sentido; ante ese mensaje los destinatarios reaccionan de muy diferentes maneras.

En el caso de Obsesivos días... la organización especial de los diferentes planos que constituyen su sentido dificulta la lectura y, por tal razón, también el proceso comunicativo mencionado arriba. El análisis de estas dificultades requiere de un modelo por medio del cual la cuestión del sentido de un texto pueda examinarse en sus aspectos comunicativos. Este modelo lo propone, por ejemplo, 
Jaap Lintvelt (1981) con base en planteamientos anteriores. El modelo de Lintvelt forma parte de los estudios acerca del point of view o perspectiva narrativa; por otro lado, ofrece un método de análisis práctico para textos narrativos. Siguiendo las observaciones de Wolf Schmid (1973) y partiendo del conocido modelo comunicativo:

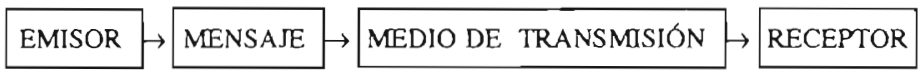

Lintvelt desarrolla un modelo de comunicación literaria. Este nuevo modelo no se limita solamente al estudio de las instancias del narrador (inarrateur fictif), de los personajes (acteurs) y del narratario (narrataire fictif), sino que considera también instancias como el autor implícito (auteur abstrait), el lector implícito (lecteur abstrait), el autor concreto o real (auteur concret) y el lector concreto (lecteur concret) (Lintvelt 9):

INSTANCIAS DEL TEXTO NARRATTVO LITERARIO: ${ }^{2}$

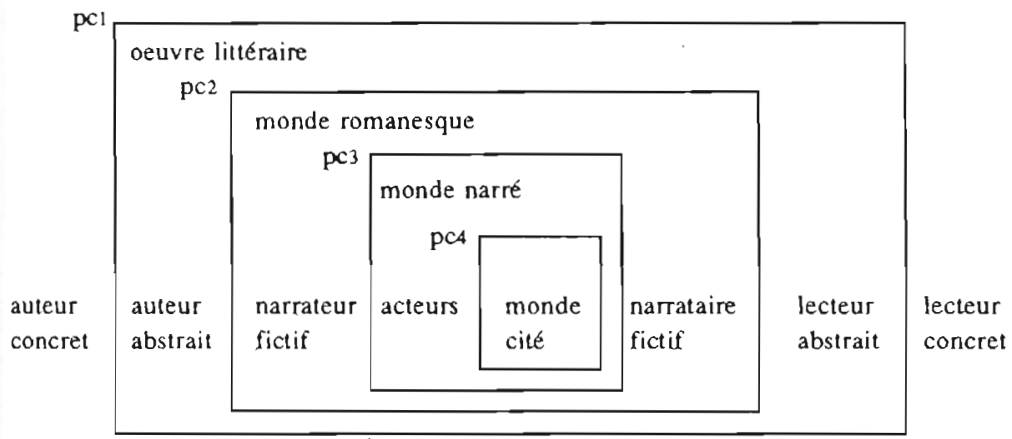

Además, Lintvelt parte de la suposición de que existe una oposición funcional entre la instancia del narrador ficticio y la de los personajes. De esta dicotomía resultan dos formas narrativas fun-

${ }^{2}$ (Lintvelt 30). La numeración de los distintos planos comunicativos es mía. 
damentales a las que, siguiendo la propuesta de Genette (1972), Lintvelt llama "narración heterodiegética" (narration hétérodiégétique) y "narración homodiegética" (narration homodiégétique). La narración heterodiegética (narración "en tercera persona") se caracteriza por un narrador cuya identidad no corresponde a la de uno de los personajes en el texto narrativo. El narrador heterodiegético, por esta razón, se encuentra fuera de la historia (o diégesis) que narra, mientras que el narrador homodiegético forma parte de la trama y debe representar un doble papel: el del narrador, como "yo narrador" (erzählendes Ich), y el del personaje como "yo namado" (erlebendes Ich).

La disposición de las diferentes instancias de un texto narrativo en el modelo de Lintvelt pone de manifiesto que el lector implícito, para enterarse del mundo narrado (monde narré), tiene que "pasar por" el narrador ficticio como mediador entre el autor implícito y la historia (monde romanesque). En las páginas siguientes intentaré demostrar cómo se presenta este acto de mediación, para poder explicar las implicaciones que tiene tal modo de presentación para la comprensión del sentido textual de la novela. Examinaré la situación comunicativa "pc3", es decir, la que comprende las instancias del narrador ficticio y del narratario ficticio, apoyándome en el modelo de Lintvelt. El análisis se ejemplifica con algunos pasajes de la obra.

Análisis de la situación narrativa

Con la lectura del episodio introductorio de la novela (9-11), el lector se entera de las intimidades amatorio-sexuales entre Sarro, el gángster gordo, calvo y pesado, y la pálida Yin. La actitud narrativa del hablante se expresa por medio de los verbos introductorios ("dice", "repite", "murmurando", etc.). Parece tratarse de un hablante "en tercera persona", esto es, de un narrador heterodiegético que no participa en la secuencia relatada y que, por eso, tampoco puede ser identificado con uno de los personajes. 
Además de descripciones de la situación y de aclaraciones en el texto ${ }^{3}$ ("Y ya en el baño, fresco y oloroso a jabón - al fondo de la recámara a la izquierda" (10)), hay otras características que se refieren a la perspectiva narrativa autorial, localizando el centro de orientación del lector implícito en el narrador. Así, el discurso autorial del narrador se manifiesta también en la compresión temporal de acontecimientos típicos que se repiten: "Después la ambigüedad de un acto cotidiano [...] que nueve de cada diez veces cuando termina [...] dice cosas como" (9). Puede asimismo identificarse una 'isotopía', ${ }^{4}$ cuyos componentes se interrelacionan a través del sema dominante que es "rutina", por ejemplo, "cotidiano", "nueve de cada diez veces", "o una costumbre", "nunca", "siempre", etc. Debido a esta isotopía, el tiempo del presente empleado pierde su efecto de indicador de simultaneidad y la escena obtiene un carácter ejemplar.

Además, el narrador posee la capacidad de moverse ilimitadamente en el espacio. En la presentación de las síguientes escenas incluso le es posible percibir el olor a jabón del baño, así como oír el ruido del agua detrás de la puerta cerrada:

${ }^{3}$ Uno de los rasgos distintivos del discurso narrativo autorial es lo que Lintvelt (61) denomina su "función narrativa" o "representativa" (fonction narrative o de représentation) que consiste en "evocar un mundo discursivo dentro del cual se desarrolla la historia" ("évoquer un monde discursif dans lequel l'histoire se déroule"). Además, el discurso autorial del narrador cumple la "función explicativa" (fonction explicative) si explica ciertos elementos de la historia ("utilisé par le narrateur pour fournir des explications de certains éléments de l' histoire" (Lintvelt 63)).

${ }^{4}$ Este término fue acuñado por Greimas. Cito de la definición que aparece en su diccionario (1982: 229-230): “1. A. J. Greimas toma prestado del dominio de la física-química el término isotopía y lo transfiere al análisis semántico dándole una significación específica, en atención a su nuevo campo de aplicación. De carácter operatorio, el concepto de isotopía designó, en un principio, la iteratividad - a lo largo de una cadena sintagmática- de clasemas [i.e., categorías semánticas desambiguadas por el contexto, como ocurre, por ejemplo, con la palabra polisémica «mono», integrándola en la oración: «el mono come un plátanos; I.M.J que aseguran al discurso-enunciado su homogeneidad". 
$Y$ ya en el baño, fresco y oloroso a jabón -al fondo de la recámara a la izquierda--, Sarro enciende una lámpara arriba del lavabo e insiste en dos preguntas antes de. ¿Un cangrejo en una maceta? Cerrar. [...] Luego, ruido de agua o una que otra palabra suelta pronunciada por Sarro al lavarse las manos, hurgar concienzudamente su nariz o verse en el espejo (10-11).

Por otro lado, la presentación escénica de hechos verbales y no verbales y el empleo icónico del lenguaje proporcionan al conjunto una calidad dramática. En la cita de arriba el acto de cerrar la puerta parece oírse verdaderamente; está sonorizado, así como la manera de hablar de Yin:

Vi un hombre, por ejemplo -inhalando-; y exhalando luego, que se arrojaba desesperado; y aspirando, contra las paredes de un hospital; y suspirando lleno de luz (9).

De modo que aquí el narrador abandona el discurso autorial para adoptar la perspectiva personal. Lo mismo vaie para pasajes como el siguiente, en el cual el narrador, haciendo uso del estilo indirecto libre, traslada el centro de orientación del lector (implícito) hacia el personaje; en este caso se trata de los pensamientos de Yin: ${ }^{5}$

es lo único que ocupa la mente de Yinyin, que no puede explicarse por qué Sarro no va más allá de la eyaculación automática, no ve nada, y por qué, sobre todo, cierra el baño como si ella. tueno vaya idea irracional (11).

La referencia al personaje corresponde al discurso del narrador. La frase "es lo único que ocupa la mente de Yinyin" prepara aquí el estilo indirecto libre. El sintagma "bueno vaya idea irracional" al final de la oración parece ser, 6 junto con el orden de las palabras, el resto no transpuesto del discurso original del personaje.

5 Estos y todos los demás subrayados son míos.

6 Digo "parece ser" porque también puede ser leído como parte del discurso del narrador que revela sus pensamientos. 
Finalmente quedan por mencionar los cambios de nombres (Sarro, Gordofofo, Yinyin, Yin) y la falta de todo tipo de explicaciones acerca del contexto situacional (por ejemplo, iquién es Donají?), que ponen de manifiesto que el narrador se dirige a un narratario que comparte determinados conocimientos de la historia relatada.

A la escena introductoria le siguen cuatro capítulos, cuyos títulos respectivos corresponden a las instrucciones luminosas en los aviones: "Fasten Seat Belt", "No Smoking", "Chalecos salvavidas bajo el asiento", "Exit". Cada uno de los capítulos permite al lector tener acceso a la vida de Terencio, el protagonista hablante "en primera persona" de la trama. Terencio es escritor y se gana la vida como portero en un colegio religioso para chicas en la ciudad de México. Está casado en segundas nupcias con Donají, quien, además de ser ama de casa, trabaja como traductora. Ambos viven en el segundo piso de una casa en el terreno de la escuela.

Detrás de la fachada de este establecimiento pedagógico, rigurosamente católico, se esconde la organización mafiosa del oscuro Papá la Oca. Este gángster mantiene a varios criminales, entre ellos a Sarro, quien tiene que esconderse de la justicia a causa de dos asesinatos. Papá la Oca le ofrece un escondrijo debajo del apartamento de Terencio y Donají; allí vive junto con su novia Yin. El edificio detrás del apartamento del protagonista limita con el vestuario de las alumnas. Un espejo preparado que separa ambas habitaciones, permite a los hombres reunidos detrás de éste -entre ellos, personajes de alto rango de la vida pública- observar a las chicas despojarse de su ropa. La tarea de Terencio consiste en atender a la clientela en "La Cripta" (así se llama esa sala) y sacar clandestinamente fotos con las cuales Papá la Oca chantajea después a su clientela.

Poco a poco el lector se entera, por boca de Terencio, de las biografías de los cuatro personajes, así como de una serie de datos acerca de su vida cotidiana. Se habla de rituales, como, por ejemplo, del baño que Terencio y su esposa toman juntos cada día, de la lectura permanentemente interrumpida del Ulises de James 
Joyce que Terencio trata de continuar, del carteo entre Terencio y Tobías Dorleado, el ex secretario de Papá la Oca, asî como de la correspondencia con Leticia Leteo, la primera esposa del protagonista. También se habla de los almuerzos comunes preparados por Donají y de las conversaciones interminables sobre música, literatura, películas, vivencias del pasado o las aventuras de Sarro.

Esta rutina diaria se interrumpe con la llegada de un telegrama que anuncia la visita de Lalka, la hermana de Yin. Sarro y Terencio van al aeropuerto para recogerla y se encuentran inesperadamente con Leticia, que está a punto de viajar a Acapulco. Espontáneamente, los dos hombres se deciden también por un viaje a esa ciudad. La partida definitiva, sin embargo, no tiene lugar hasta el final del primer capítulo. A causa de un incidente dramático - Sarro sufre una embolia y es internado en el hospital- no pueden continuar los preparativos del viaje.

En el transcurso del primer capítulo, el lector se entera de dos pasiones de Terencio que juegan un papel decisivo para el análisis de la situación narrativa de la novela:

El monstruo protesta desde el baño y Yin se levanta, insistentemente desnuda. Por verla mejor me golpec contra el suelo. [...] Observar el baño significa retirar con excesivas precauciones la cubierta de un espejo de doble vista que desde la casa de Globohinchado parece gigantesco adorno art-nouveau (64).

Resulta que Terencio es un voyeur profesional. Su predilección por espiar la vida privada de otros lo indujo a preparar el piso de su apartamento y a colocar un espejo de tal manera que le es posible observar a la pareja en cada una de sus habitaciones.

La otra pasión del protagonista es la de escribir cartas, dato que ya se desprende de la cantidad de encabezamientos dispersos por toda la novela. Sin embargo, en total aparecen solamente tres unidades de texto identificables como cartas concluidas por el hecho de que exhiben formas convencionales como el encabezamiento "Querido Joderías:" (62) y el saludo al final: "Tu seguro vulcanizador y atento charro/" (63). Además de estas tres cartas com- 
pletas, existen aproximadamente cuarenta sintagmas que se refieren a un destinatario, sugiriendo la suposición de otras cartas fragmentarias. Aquí no se trata solamente de encabezamientos (saludo y dos puntos) o imperativos ("Y evoca para ti, Jorobas" (76)), sino que el hablante se refiere también, indirectamente, a un destinatario al emplear preguntas retóricas como la siguiente: "¿Dije que también hablamos de Fray Servando Teresa de Mier?" (41). Como lo muestra la cita, las expresiones referenciales no nombran siempre explícitamente al destinatario, de manera que el lector no tiene que identificarlas con uno de los corresponsales de Terencio.

Dificulta la comprensión del texto el hecho de que no sean fijos los límites entre estos fragmentos de cartas y las unidades de cartas conclusas. Ciertamente, formulas de saludo, renglones de puntos, párrafos y rayas que rompen unidades sintácticas, en primer lugar, sugieren la conclusión de la carta respectiva. Sin embargo, unas líneas más adelante aparece una nueva referencia al destinatario. Estas características dan al lector la impresión de que toda la novela consiste en una sucesión de cartas.

Como el texto presenta muy pocos elementos que permitan identificar estas relaciones entre Terencio y sus corresponsales como actos comunicativos escritos, podría suponerse que la trama se manifiesta como un interminable monólogo interior del protagonista, que es lo que probablemente pensó David Decker (Sainz 1979, Epílogo 340) al decir un tanto vagamente que en esta obra "todo el diálogo está incorporado al interminable monólogo del narrador, debido a la ausencia de una puntuación aclaratoria". Esta hipotesis se impone sobre todo en aquellos pasajes que, aparte de exhibir un predominio de la presentación escénica, así como el continuo empleo de la primera persona singular del presente, no contienen ninguna indicación acerca de la existencia de una relación comunicativa. Este caso se da al final del segundo capítulo, que presenta el viaje de Donají, Yin, Lalka y Terencio de Acapulco a la ciudad de México. El pasaje está encuadrado por dos expresiones referenciales. Por un lado, la pregunta retórica " ¿Te lo 
escribí, Jorobas?" (146) y, por otro, el saludo "Querido Jorobas..." (185). Entre estos dos sintagmas hay cuarenta y tres páginas de texto en las cuales el hablante no nombra a ningún destinatario.

Teóricos de las estructuras narrativas como Silvia Burunat (1980), Wolf Schmid (1973) y Jürgen Zenke (1976) definen el monólogo interior como forma discursiva muda y no mediada "en primera persona", que sirve para revelar los sentimientos, pensamientos, opiniones o dudas más íntimos de un personaje. Puede además abarcar toda una gama de diferentes grados de conciencia: tanto deseos y pensamientos como sueños inconscientes y también casi conscientes. Este modo de presentación se refleja también en la estructura lingüística. Si se toma como base esta definición, se encuentra en Obsesivos días... una serie de ejemplos que sí revelan la existencia de un narrador:

A las seis y media salimos hacia México. La carretera sinuosa y el cielo restirado como la piel de un jabalí antes del curtido son del mismo color. Tengo vista cansada, ojos secos y Trusa, sentada junto a mí, anuncia la presencia de burros o caballos que pueden estrellarse contra nosotros. Al fondo del camión, que traquetea como si fuera desarmándose, Yin y Dona cuchichean. Quiero oír pero al mismo tiempo tengo que atender al camino y me fatigo muchísimo (149).

Aquí, la actitud narrativa se manifiesta en indicaciones de tiempo y lugar o en descripciones de lugar y del estado de ánimo del protagonista, que explicitan el discurso y dirigen la atención hacia la situación comunicativa. El empleo continuo de formas verbales del presente, sin embargo, así como la tendencia a la presentación escénica de actos verbales y no verbales, trasladan el centro de orientación del lector implícito hacia el yo narrado del protagonista. En el transcurso de esta secuencia de la trama, la voz mediadora tiende a pasar a segundo término, de manera que el foco de presentación se concentra en la perspectiva de Terencio manejando el camión. Pero la eliminación total del yo-aquí-ahora (Bühler 1934), en el sentido de la definición del monologo interior, solo 
tiene lugar en unos pocos pasajes del texto. Esto vale, por ejemplo, para el siguiente párrafo:

¿Y si chantajeara a los voyeuristas? Tengo que proponérselo a Dona, son puros peces gordos. Y la fiesta en el penthouse, los apagones. Supongo que Yin cachondeaba a placer con alguno de los arquitectos aprovechando las repetidas tinieblas. Volvía la luz y ella se portaba fría y como si nada. En la alberca él seguramente, o a la mejor hablando por su amigo, le decía que no lo olvidara cuando estuviera en su reino de placeres prohibidos: Checan, Kama Kala, Shunga, The Story of O, Les 120 Journées de Sodome. Y anoche Yin fue a su encuentro $o$ a una cita en la playa y siguió soltándole cuerda hasta que llegaron a las manos. Entonces, miedosa de destruir un hogar, cristiana como es, lo mandó al carajo. $\mathrm{O}$ los mandó. A lo peor entusiasmó a los dos. ¿O es que temo que le hayan dado lo que yo no pude? (149).

En primer lugar son las preguntas retóricas las que señalan la existencia del monólogo interior: " $¿ \mathrm{Y}$ si chantajeara a los voyeuristas?", ¿O es que temo que le hayan dado lo que yo no pude?" Además, el contexto da motivo a la suposición de que se trata de un monólogo mudo y no de un soliloquio; Lalka está sentada al lado de Terencio en el camión y conversa con él de vez en cuando. El viaje de noche le cansa mucho, y le costaría gran esfuerzo concentrarse al mismo tiempo en la conversación de las dos mujeres en el fondo del autobús. Por eso se desconecta del mundo exterior y da rienda suelta a sus pensamientos. Aparte, el texto muestra una de las formas sintácticas que son características de la presentación de pensamientos: la elipsis ("Y la fiesta en el penthouse, los apagones. [...] Volvía la luz y ella se portaba fría y como si nada. En la alberca él seguramente, o a la mejor hablando por su amigo").

El paso de construcciones sintácticamente completas a formas elípticas en este ejemplo alude a los diferentes grados de conciencia que puede abarcar el monólogo interior. La estructura lógica del contenido y el mantenimiento, en gran parte, de las reglas de la sintaxis española demuestran, sin embargo, que la presentacion 
se concentra en el contenido de la conciencia de Terencio (yo narrado).

Mucho más difícil es la clasificación de los siguientes pasajes como ejemplos de monólogo interior. Así, la conversación entre Donaji y Yin sobre Sarro y sus aventuras (157) lleva a Terencio a evocar la imagen de un Sarro desmayado en una cama del hospital. La suposición de un cambio de perspectivas - de la presentación de la trama a la imaginación o conciencia del protagonista- está motivada en este caso por el contexto situacional. El hecho de que al final de esta secuencia de recuerdos - que se destaca también del texto restante por medio de un apartado- no haya ningún comentario por parte de los personajes presentes (véase también la observación de Donají que sigue a esta secuencia), admite la conclusión de que probablemente se trata de una presentación de impresiones, opiniones, etc., de Terencio, en forma de un monologo interior:

Y el gordo en el hospital, como una montana en un paisaje de José María Velasco, el blanco e imponente Popocatépetl, o las accidentadas cumbres del Iztaccíhuatl, nuestros ojos revisándolo desde atrás de una puerta de vidrio: las agrestes amugas, cañadas de lana y comezón, la carne brillante y la cabezota redonda y fuerte como las cabezas gigantes de Tula, grises y petrificadas al pie de las pirámides. Y las amplias sábanas blancas, tan blancas como las paredes, pero onduladas/

La carretera describe un amplio círculo hacia la derecha, para salvar un atrayente abismo; parece una curva inútil: un puente hubiera bastado. Pero la montaña también, pequeña y huesuda, parece una de las rodillas de Sarro, y el camino es blando y sin obstáculos, como una sábana, y vamos a noventa kilómetros por hora pero no logramos dejar atrás la enorme panza del gordo y es como si marcháramos sobre una tira de Moebius. Y el asesinato de Jaramillo dice Dona (157).

La curva a la derecha que la carretera describe inesperadamente corta el flujo de pensamientos de Terencio en medio de una unidad sintáctica. Este corte está puesto de relieve por medio de la 
raya. Es así como la percepción visual se verbaliza y, de este modo, se presenta a través de un mediador. Sin embargo, es la imagen de una montaña la que hace que Terencio vuelva al mundo de sus pensamientos y se emplee otra vez el monólogo interior.

Las dificultades que han surgido al diferenciar las distintas posiciones del hablante Terencio se deben al modo como se presentan los actos verbales y no verbales. Con respecto a esto, el párrafo analizado es representativo de toda la novela.

Desde el punto de vista meramente óptico, la extensión del texto dedicado a esta secuencia de la trama da la impresión de una correspondencia en duración entre el tiempo de lo presentado y el tiempo de la presentación. Esta impresión se apoya en la circunstancia de que el yo narrador tiende a la presentación escénica de actos tanto verbales como no verbales. Este recurso estilístico, por medio del cual se trata de presentar procesos temporales en su duración real, proporciona calidad dramática a la trama y da al lector implícito la impresión de participar en ella. Además, el empleo del presente causa esta pseudo simultaneidad entre la presentación y lo presentado, acercando de este modo el yo narrador al yo narrado. Es cierto que la falta de puntuación para marcar el discurso de personajes, así como el sumamente escaso empleo de formulas introductorias (a veces es sólo un "y"), señalan la reducción de la mediación. Pero resulta que, por razones relacionadas con la comprensión, no se puede renunciar del todo a ellas. Un ejemplo ilustra la técnica:

Esa agenda del Gordo, recuerdo, esa libreta negra que carga siempre, ¿estará en casa? Es posible dice Yin. Me gustaría hojearla. Tendriamos que pedirle permiso. No ése no es el caso. Mira, será 0 no el caso, pero si tienes mucho interés en saber lo que hace para Papá la Oca, por qué no le preguntas. Es que no puede hablar, está paralizado. ¿Cómo sabes? A lo mejor volvió a la escuela dice Lalka (159).

La conversación comienza con la introducción de los interlocutores por medio de los sintagmas "recuerdo" y "dice Yin". La 
identificación de los distintos discursos con respecto a los personajes no es difícil, primero, porque se trata solamente de dos interlocutores $y$, segundo, porque el medio exige el respeto a ciertas reglas de comunicación para el cumplimiento de actos comunicativos. A diferencia de lo que pasa en los textos dramáticos, los discursos de varios personajes en textos narrativos sólo pueden ser presentados uno tras otro, aunque esta presentación no corresponde al proceso comunicativo natural del hombre. Hay que añadir que las preguntas de un personaje son contestadas por su interlocutor ("¿Estará en casa? Es posible”) y las afirmaciones son refutadas ("Tendríamos que pedirle permiso. No ése no es el caso. Mira, será o no el caso pero").

Aparte de que la voz del mediador no puede ser omitida del todo, hay otros aspectos que impiden la clasificacion de semejantes pasajes como parte de un interminable monólogo interior. El solo hecho de que conversaciones enteras -como en el ejemplo citado- estén reproducidas palabra por palabra, hace inverosímil un monólogo interior, cuanto más que estos diálogos están presentados claramente como parte de la trama y no como actos imaginados. Esto ocurre cuando Terencio se retira del mundo exterior para dirigir el foco de su discurso a su imaginación, cambio marcado incluso gráficamente por medio de rayas o anunciado explícitamente por la voz del narrador.

No la atiendo y pienso en Sandino con las manos en los bolsillos, sentado junto a Umanzor y Estrada en algún promontorio, en alguna parte de la noche, y en un mayor que delegó el mando y en varias ametralladoras descargándose sobre los tres hombres, despellejándolos, y en un montón de campesinos oyendo los disparos, colores en su noche de marihuana, y corriendo a ocultarse tras un camión de redilas, ascendiendo laderas con caminitos serpenteantes entre pastizales y piedras, persiguiéndose, rodando, besando la tierra, mordiéndola, y reduzco la velocidad. ¿A Maximiliano lo fusilaron de día o de noche? De día, dice Dona (157158). 
do ("No la atiendo y pienso en") y los estructura "narrativamente", lo que está expresado por la repetición reducida del sintagma "y pienso en", en forma de "y en". Durante un momento, estos pensamientos -mediados por el yo narrador- monopolizan por completo su concentración, de manera que Terencio ya no puede seguir la conversación entre Yin y Donají. Sin embargo, muy pronto tiene que volver a prestar atención al camión; reduce la velocidad, un acto que hace que Terencio vuelva a los hechos exteriores, pudiendo conectarse nuevamente a la conversación de las mujeres.

Una serie de indicios han comprobado que en el caso del ejemplo aquí tratado (el viaje de regreso a la ciudad de México) no se puede hablar de una presentación en forma de un interminable monólogo interior. Si bien es cierto que con este modo de presentación el autor implícito trata de reducir la voz del narrador y, en parte, de eliminarla por completo, también es obvio que los ejemplos escogidos han podido ilustrar que la mediación orientadora del narrador no puede ser suprimida por completo. Su empleo en el diálogo de los personajes está tan exactamente calculado, que basta para asegurar la comprensión del lector implícito. Si el autor implícito hubiera renunciado también a estas últimas huellas de mediación, no habría podido postular a un lector implícito capaz de identificar los distintos discursos de los personajes.

El hecho de que el párrafo de texto analizado aquí muestre un modo de presentación que, una y otra vez, se traslada hacia la perspectiva del yo narrado, dificulta la diferenciación entre el monólogo interior y otra forma de discurso que hasta ahora no ha sido considerada debidamente: el estilo indirecto libre "en primera persona singular". El estilo indirecto libre, a diferencia del monologo interior, implica un relato desde un yo-aquí-ahora distinto del sujeto cuyo discurso se registra. Los problemas del párrafo comentado aquí se deben al empleo de los tiempos verbales. ¿Se trata de un presente con referencia al presente del yo narrador o al presente del yo narrado (al pasado)? ¿Puede ser que la diferencia de lugar y/o la retrospectiva, como rasgos decisivos del estilo indirecto li- 
bre, no estén marcadas aquí? La respuesta es imposible porque se trata de un párrafo que sigue directamente a un fragmento de car$\mathrm{ta}^{7}$ (de manera que se podría suponer que la secuencia presentada en este párrafo forma parte todavía de la carta, precediendo, por eso, temporalmente al acto de escribir) y porque no hay ninguna indicación que lo identifique como carta.

Con el fin de resumir el modo de presentación en ese párrafo, propongo la siguiente caracterización: se trata de una narración escénica, homodiegética personal que varias veces, según queda comprobado, pasa al monólogo interior. Estando redactada en el tiempo del presente toda la presentación sin que esté marcada claramente la referencia temporal de este presente, llegan a surgir inseguridades con respecto a la identificación del discurso de Terencio como monologo interior, estilo indirecto libre o soliloquio.

Luego de haberme dedicado principalmente a ejemplos del primero y segundo capítulos de la novela, quiero concentrar el análisis de la instancia del hablante en algunas peculiaridades de la tercera y cuarta partes.

Después de los días de vacaciones en Acapulco y del regreso a la ciudad de México, el tercer capítulo vuelve sobre la rutina diaria del protagonista. Una de las escenas relatadas en esta parte muestra a Donají y a Terencio durante su baño diario. La conversación entre los dos es interrumpida de vez en cuando por la revelación de los procesos que se llevan a cabo en la conciencia de Terencio. Después de que Donají ha salido de la bañera para contestar el teléfono, el lector "está solo con el protagonista", el cual se deja llevar por sus pensamientos. Aquí — Terencio finalmente se decide a quitar el tapón de la tina - aparecen de repente las siguientes palabras:

Querido Jorobas... Quito el tapón de la bañadera. Tras una larga pausa el agua baja de nivel, suavemente, luego un poco más aprisa, cada vez más aprisa, hasta arremolinarse, convergir, entor- 
narse y desaparecer con un eructo casi geológico. Pequeñito pero antinatural, o demasiado natural quizás, animal inclusive. Vuelvo a tapar el desagüe y abro la llave de vaporosa agua caliente, la otra también: hay que calcular, es demasiado caliente al principio. Y me recuesto. El teléfono ha dejado de sonar, pero no alcanzo a escuchar la voz de Dona/ (189).

En este contexto no resultaría verosímil identificar el discurso dirigido a "Jorobas" como carta (además, se trata del único encabezamiento que no está seguido por dos puntos), ya que un hombre no es capaz de realizar dos actos tan diferentes -quitar el tapón de la bañera y escribir cartas - al mismo tiempo. La situación sugiere, más bien, interpretar el pasaje como el reflejo de los pensamientos de Terencio durante este acto. También los tres puntos suspensivos pueden ser leídos de este modo. Luego sigue la descripción de lo que Terencio está haciendo ("Quito el tapón") y de lo que está percibiendo ("Tras una larga pausa"). La próxima oración no presenta ninguna huella de mediación. Son los pensamientos del yo narrado en forma de un monologo interior, al observar cómo está desapareciendo el agua en el tubo de desagüe: "Pequeñito pero antinatural, o demasiado natural quizás, animal inclusive". Y otra vez se produce un cambio de perspectivas del yo narrado al yo narrador: "Vuelvo a tapar". Dos puntos introducen, finalmente, el monólogo interior directo del protagonista: "hay que calcular, es demasiado caliente al principio". Cierra el ejemplo una descripción de lo que Terencio está haciendo después: "Y me recuesto".

Sigue la trama con un recorte, que no se distingue tipográficamente, de un artículo de periódico en lengua portuguesa. Los pormenores de este artículo ya se dieron unas páginas antes. Resulta que forma parte de una carta que recibio Terencio y cuyo contenido no se podía explicar. El lector implícito ya ha tenido la ocasión de observar a Terencio leyendo este artículo por partes (en la sala de espera del hospital y en la bañera). Sin embargo, aún no puede enterarse del artículo completo porque el protagonista interrumpe la lectura en medio de la oración (190). Esta ruptura está marcada 
por una raya y el comienzo de un nuevo párrafo, que va seguido de una carta a Tobías, esta vez con encabezamiento y dos puntos.

No se puede decir con seguridad, ni en este ni en ninguno de los demás pasajes mencionados hasta ahora, si se trata de la realización de un acto de escribir o, como hay que suponer en el ejemplo de Terencio en la bañera, de la construcción imaginaria de una relación comunicativa, ya que faltan las correspondientes explicaciones.

Los fragmentos de cartas se encuadran en la cronología de las secuencias de la trama sin que estén marcados como tales. Tampoco el contexto situacional ofrece una indicación cierta. A causa de este modo de presentación surge la impresión de una serie de cartas que son meros productos de la imaginación del protagonista. El hecho de que esta impresión es obviamente engañosa se revela en unos pocos pasajes que fácilmente pueden ser saltados en la lectura. Una de estas indicaciones se halla en el último capítulo de la novela. Esta parte continúa desarrollando los hechos presentados en el capítulo anterior. A causa de la despedida de Yin, su inesperada desaparición, la caída de Lalka a través del espejo de La Cripta y la revelación del proposito real de esta construcción, Terencio recibe la orden de ejecutar una misión misteriosa en Acapulco. El capítulo lo muestra a bordo de un avión en dirección a la ciudad costeña. Resulta que los demás pasajeros son empleados de Papá la Oca. Y para Terencio se confirma la sensación de que el verdadero objeto de la misión es su eliminación. Con el fin de distraerse, escribe una carta a su amigo Tobías.

Aquí se echa de ver que Terencio formula por lo menos parte de sus cartas por escrito. La siguiente cita también demuestra explícitamente que junto a la exposición de sensaciones y pensamientos, hay asimismo un mundo exterior, lo que ya se desprendió del análisis de la escena del viaje en camión. El proceso de escribir es interrumpido por las palabras:

Guardo la pluma y doblo la carta iniciada para Jorobas. ¿Para qué escribo si van a encontrarla semidestruida sobre mi pecho carbonizado, cuando revisen los cadáveres? (242). 
Todas estas observaciones indican que hay que interpretar las relaciones comunicativas entre Terencio y sus corresponsales - ya sea que existan sólo en la imaginación o estén puestas por escrito- como partes de la historia, como componentes de un relato delimitado. Aquellos párrafos que contienen fragmentos de cartas cumplen la función de ser junturas entre unidades epistolares conclusas y el resto de la presentación de la trama. Si el autor implícito no hubiera empleado este artificio, si hubiera insertado solamente cartas conclusas que se encuadraran en el relato "pc3", no habría tantas dificultades con respecto a la determinación tipologica de la instancia del hablante. Sin embargo, el hecho de que cartas, fragmentos de cartas y el resto del relato estén tan engranados, haciendo imposible para el lector la diferenciación entre las distintas unidades de relato, vuelve imprescindible un análisis que examine separadamente cada una de las tres formas de relato con respecto a su situación comunicativa.

Mientras aquellos párrafos que abarcan unidades de cartas conclusas presentan a Terencio, el protagonista, como narrador con una intención mediadora dentro de una situación comunicativa donde también se involucra a Tobías o Leticia, semejante relación comunicativa siempre se constituye en los párrafos con referencias explícitas a alguno de estos corresponsales. Sin embargo, en algunos pasajes el análisis ha demostrado la existencia de una instancia mediadora, pero no ha sido posible determinar concretamente la relación comunicativa en que la misma se enmarca. La dificultad se debe a la ya mencionada inserción de fragmentos de cartas. Este recurso hace que el lector se halle ante un montón de dudas y preguntas no aclaradas. Mientras que pasajes como los del viaje en camión dan la impresión de que, aparte de la relación comunicativa entre Terencio y sus corresponsales, existe ofra entre el protagonista y un narratario ficticio, esta impresion muy pronto es suprimida por los pasajes de cartas inconclusas, pues llevan al lector a suponer que unidades como la del viaje forman parte de una carta muy larga, es decir, que existe una sola relación comunicativa en forma de carta entre Terencio y su corresponsal. 
Sólo el análisis detallado de estos fragmentos de carta nos proporciono la clave del secreto. En el último capítulo de la novela se halla un pasaje en el cual el narrador Terencio arroja luz sobre la situación. Allí aclara que el proceso de escribir también se interumpe, que aparte de las cartas a Tobías y Leticia hay una trama en la cual participa. Con esta indicación las cartas y los fragmentos de carta se presentan como partes de un marco narrativo superior. Terencio, presentándose como el autor de las cartas, es el narrador tanto del plano "pc3" como del plano "pc4". Como la instancia del hablante en ambas situaciones narrativas se refiere a acontecimientos del presente, esto es, como en ambas situaciones hace uso del tiempo verbal del presente, y el narrador de las cartas no se diferencia explícitamente del narrador extradiegético (Lintvelt 210), entonces se superponen los dos planos narrativos. Sin embargo, como se verá, no se puede resumir la estructura comunicativa de toda la trama en un solo esquema.

\section{La superposición de planos comunicativos}

y su construcción en forma de cajas chinas

Las diferentes secuencias de la trama están concatenadas en el plano del contenido por medio de leitmotivs temáticos. Uno de ellos se manifiesta en la imagen recurrente de la incontrolable multiplicación de objetos, como, por ejemplo, la tortuga de Lalka, de cuyo interior aparecen nuevas tortugas cada vez más pequeñas cuando Terencio la abre (54). Esta imagen reaparece en forma modificada cuando el protagonista recoge la ropa que Yin lanz 6 de la maleta. En ese momento Terencio tiene la sensación de que la ropa se multiplica (90). El tercer ejemplo del leitmotiv se manifiesta en la escena en la cual Terencio mira las palmas de sus manos, persiguiendo la línea de vida, cuyas ramificaciones vuelven a ramificarse infinitas veces (193).

Estamos aquí frente a una de las obsesiones del protagonista: su temor a que actos y situaciones puedan independizarse de modo 
que pierda el control sobre ellos. Y es esto lo que finalmente sucede. La rutina diaria es internumpida por la paulatina acumulación de acontecimientos imprevistos, como ya hemos podido comprobar. La desorientación, la confusión y el miedo van aumentando hasta desembocar en la absoluta incapacidad de actuar del protagonista (véanse las páginas finales de la novela).

El leitmotiv de la incontrolable multiplicación de objetos se repite en el plano de la expresión en forma de la superposición, o mejor, de la construcción de planos comunicativos en forma de cajas chinas. El capítulo "Fasten Seat Belt" abre con el siguiente fragmento:

Imponente y rollizo, Buck Mulligan apareció en lo alto de la escalera con una bacía desbordante de espuma, sobre la cual traía cruzados un espejo y una navaja/ (15).

Se trata de las líneas introductorias del Ulises traducidas al castellano (Joyce 1986 3): "Stately, plump Buck Mulligan came from the stairhead bearing a bowl of lather, on which a mirror and a razor lay crossed". El hablante, sin embargo, omite cualquier tipo de referencia; sólo por medio del contexto situacional el lector llega a saber que presencia un proceso de lectura en forma de un monólogo interior: "y me hace levantar la vista del libro y murmurar qué" (15). La raya después de la cita del Ulises destaca gráficamente la interrupción de la lectura. Son las palabras de Sarro que entra, como explica luego el yo narrador: "Voyme tomorrow, viejito, chabocho trabajo cayóme. Y es el gordo Sarro que intemumpe" (15). La deliberada renuncia a la intervención organizadora por parte del narrador le otorga a la secuencia cualidad dramática, causando al lector la impresión de que él también es interrumpido continuamente en su lectura: "Y es el gordo Sarro que intemumpe, $\tan$ imponente y rollizo como, y me hace levantar la vista y murmurar que" (15).

Lo que destaca es la ruptura del discurso o anacoluto, que, en vez de terminar la unidad sintáctica, comienza con una nueva oración. Aquí el anacoluto se emplea como un recurso estilístico 
para acentuar más plásticamente la interrupción por parte de Sarro y Donají y el acto de levantar la cabeza. En la presentación del siguiente diálogo entre Sarro y Donají — que Terencio puede oír sólo parcialmente, pues está ocupado todavía con la lectura del Ulises - se pone de manifiesto cómo se esfuerza el autor implícito por reducir la distancia entre la narración y lo narrado al presentar los hechos desde el punto de vista de Terencio protagonista. Y una y otra vez el texto se convierte en el monologo interior del protagonista que vuelve a su libro:

Traigo esto, agrega, y sus hinchados, torcidos brazos de tubo de desagüe muestran una bandeja rebosante de ropa sucia sobre la cual brillan dos recipientes de rapé ¿o tres? Un obsequio escupe con pronunciación laboriosa, como quien está a punto de eructar, y hola, Donají. Quihubo: desde la cocina. Me vine a despedir, y sefiala los estuchitos plateados, iba a tirarlos. Apareció en lo alto de la escalera con una bacía desbordante de espuma. Los iba a tirar (15).

S6́lo al final de estas líneas la voz del mediador homodiegético personal interviene para diferenciar entre la trama de la cual él mismo forma parte y la secuencia de la trama del Ulises:

Pero no el cinemascópico Sarro, sino Mulligan en la primera página de Ulysses, el ronente e impollizo libro que estoy dispuesto a devorar (15).

El modo de presentación elaborado hasta este pasaje de texto se puede esquematizar de la siguiente manera:

\begin{tabular}{l} 
pc3 \\
\begin{tabular}{|l|l|}
\hline mundo novelesco & pct \\
narrador extradie- & $\begin{array}{l}\text { discurso diegético } 1 \% \\
\text { historia } 1 \% \text { diégesis/ } \\
\text { personajes } 1^{\text {os }} \text { diegé- } \\
\text { ticos: Terencio, Yin. } \\
\text { Donají, Sarro }\end{array}$ \\
\hline
\end{tabular} \\
\hline
\end{tabular}


Sin embargo, cuando Sarro comunica a Terencio que la directora quiere hablar con él urgentemente, otra vez éste tiene que interrumpir la lectura del Ulises. Se traslada hacia la oficina de la directora para verse enfrentado con la familia de una alumna. La situación comunicativa descrita amiba se quiebra a causa del siguiente discurso de un personaje: “¿Siquiera abrieron las ventanas? pregunta Donají cuando narro lo sucedido. No" (19).

Resulta que todo lo que ha ocurrido hasta esta cita es el objeto de una narración enmarcadora. En lugar de una instancia narrativa del plano comunicativo 3 , esto es, un narrador extradiegético que se dirige a un narratario ficticio, se trata de un narrador que personalmente forma parte de una historia mediada, dirigiéndose como instancia "(intra)diegética" (Lintvelt 210) a un público explícitamente nombrado.

A causa de la superposición de dos planos comunicativos, el yo narrado del plano comunicativo 4 se transforma en el yo narrador del plano comunicativo 3, que informa - desde una distancia temporal y espacial - sobre un hecho concluido en el pasado. Este cambio de perspectivas también tiene su efecto en los tiempos verbales. Si la secuencia de la trama ha sido estructurada hasta este pasaje por medio de formas verbales en presente,

Silencio reptan las monjas y se oyen cifras probablemente equivocadas, cómo voy a saberlo, pues las puertas se abren y muestran un grupo familiar [...] (19),

ahora es la situación narrativa la que "avanza" hacia el presente y de este modo al foco de la presentación. El objeto de la narración que está en el pasado se marca con formas pretéritas: "Sí, dice Yin, y qué pasó" (19).

Considerando estas nuevas relaciones, el anterior esquema comunicativo tiene que ser modificado (Lintvelt 213): 
pc3

\begin{tabular}{|c|c|c|c|c|}
\hline \multirow[t]{2}{*}{ mundo novelesco } & \multicolumn{3}{|c|}{$p c 4$} & \\
\hline & $\begin{array}{l}\text { discurso dieg } \\
\text { personajes } 1 \\
\text { Terencio, Yi }\end{array}$ & $\begin{array}{l}\text { ico } 1^{\circ} \text { Mistoria } 1 \% \\
\text { diegéticos: } \\
\text { Donají, Sarro } \\
\text { pc5 }\end{array}$ & & \\
\hline $\begin{array}{l}\text { narrador } \\
\text { oextradiegético: } \\
\text { Terencio }\end{array}$ & $\begin{array}{l}\text { narrador } 1^{\circ} \\
\text { diegético: } \\
\text { Terencio }\end{array}$ & $\begin{array}{l}\text { discurso diegético } 2 \% \\
\text { historia } 2^{2} / \\
\text { personajes } 2^{\text {os }} \\
\text { metadiegéticos: } \\
\text { Terencio, la directora } \\
\text { la alumna y su familia }\end{array}$ & $\begin{array}{l}\text { nartalario } \\
1^{\circ} \text { diegético } \\
\text { Yin, Donají, } \\
\text { Sarro }\end{array}$ & $\begin{array}{l}\text { narratario } \\
\text { extradiegético: } \\
\text { namatario } \\
\text { ficticio }\end{array}$ \\
\hline
\end{tabular}

Este esquema tiene que ser ensanchado por otro plano comunicativo, en el cual Terencio cumple nuevamente la función del narrador. Se trata del papel que desempeña cuando relata su opinión del caso a los que están presentes. De este modo, el lector implícito trata con un protagonista que cumple la función del narrador en los tres planos comunicativos superpuestos. Además, en la última historia narrada, la más intema, desempeña el papel del protagonista. De acuerdo con estas reflexiones, hay que modificar el esquema de la siguiente manera:

\begin{tabular}{|c|c|c|c|c|c|c|}
\hline \multicolumn{7}{|c|}{ mundo novelesco } \\
\hline & \multicolumn{5}{|l|}{$p<4$} & \\
\hline & \multicolumn{4}{|c|}{$\begin{array}{c}\text { discurso diegético } 1^{\circ} \text { historia } 1 \% \\
\text { personajes } 1^{\text {o* Terencio, Y in. Donaji, Sarto }} \\
\text { pC5 }\end{array}$} & \multirow{5}{*}{$\begin{array}{l}\text { namatario } \\
1^{\circ} \text { diegéti- } \\
\text { co: } \\
\text { Yin, Dona- } \\
\text { ji, Sarto }\end{array}$} & \\
\hline namador extra & narrador $1^{\circ}$ & \multicolumn{3}{|c|}{ discurso diegético $2 \%$ bisturia $2 \%$ personajes $2^{\text {cot }}$} & & namatario \\
\hline diegético: & diegético: & meladiegéticos: & pc6 - n & & & extradic- \\
\hline Terencio & Terencio & $\begin{array}{l}\text { Terencio, la directo- } \\
\text { ra, la alumna y su } \\
\text { familia } \\
\text { narrador } 2^{\circ} \text { metadie- } \\
\text { gético: Terencio } \\
\text { la alumma }\end{array}$ & $\begin{array}{l}\text { discurso dic- } \\
\text { gético } 3 \% \\
\text { historia } 3 \% \\
\text { personajes } 3^{\circ} \text { : } \\
\text { Terencio, la } \\
\text { alumna }\end{array}$ & $\begin{array}{l}\text { nartatario } \\
2^{\circ} \text { meta- } \\
\text { diegético: }\end{array}$ & & $\begin{array}{l}\text { tico: } \\
\text { narratario } \\
\text { ficticio }\end{array}$ \\
\hline & & & & $\begin{array}{l}\text { Tere ocio, } \\
\text { la directo- } \\
\text { ra, la alura- } \\
\text { na y su fa- } \\
\text { milia. }\end{array}$ & & \\
\hline
\end{tabular}


Una vez reconocida esta superposición, el lector no tiene dificultades para relacionar los distintos discursos de personajes con los planos discursivos correspondientes. Una raya corta el diálogo entre la madre, la alumna y la directora en la historia $3^{a}$ en medio de la oración. Después de un párrafo sigue, directamente y sin introducción narrativa, una carta de Terencio a su amigo Tobías en Brasil: "Estimado Jobito: recibimos hoy carta tuya. Comencé a leerla antes de comer" (20).

La carta tiene como contenido la conversacion (que ahora pertenece al pasado) entre Yin, Sarro, Donají y Terencio durante el almuerzo. La cita de la pregunta de Yin "Y ya habías tenido otros problemas con las alumnas ¿verdad?" (21), se refiere directamente al tema de la discusión en la oficina de la directora. Toda esta secuencia de la trama - la conversación entre Terencio, Yin, Donají y Sarro - se presenta cronologicamente. Sin embargo, se desenvuelve en un nuevo plano comunicativo, el "pc3", "dentro" de la carta. Terencio sigue siendo el mediador de los hechos, pero ahora se dirige a Tobías Dorleado. El esquema comunicativo esbozado arriba tiene que ser modificado otra vez:

pc3

\begin{tabular}{|c|c|c|c|c|c|c|}
\hline mundo novel & lesco & & & & & \\
\hline 16. & $\begin{array}{l}\text { discurso die } \\
\text { personajes } 10\end{array}$ & $\begin{array}{l}\text { ético l\%Mistoria l\% } \\
\text { : Terencio. Tobiss } \\
\\
\end{array}$ & & & & \\
\hline $\begin{array}{l}\text { narrador ex- } \\
\text { tradiegético: }\end{array}$ & $\begin{array}{l}\text { namador } 1^{\circ} \\
\text { diegético: }\end{array}$ & $\begin{array}{l}\text { discurso diegético } 2 \\
\text { metadiegéticos: }\end{array}$ & $\begin{array}{l}\text { historia } 21 / \text { person } \\
\text { per }\end{array}$ & ies 200 & $\begin{array}{l}\text { narratario } \\
\text { lo diegéti- }\end{array}$ & $\begin{array}{l}\text { namatario } \\
\text { extradie- }\end{array}$ \\
\hline Terencio & Terencio & $\begin{array}{l}\text { Terencio, Yin, } \\
\text { Donaji, Samo } \\
\text { famitia } \\
\text { narrador } 20 \text { meta- } \\
\text { diegético: Sarro, } \\
\text { Terencio }\end{array}$ & $\begin{array}{l}\text { discurso die- } \\
\text { gético } 3^{\%} \% \\
\text { historia } 31 / \\
\text { personajes } 3^{\text {os }}\end{array}$ & $\begin{array}{l} \\
\text { rúrratirio } \\
2^{\circ} \text { metadie- } \\
\text { gético: }\end{array}$ & $\begin{array}{l}\text { co: } \\
\text { Tobías }\end{array}$ & $\begin{array}{l}\text { tico: } \\
\text { Namatario } \\
\text { ficticio }\end{array}$ \\
\hline
\end{tabular}


Los cambios en la estructura comunicativa, la construcción y desconstrucción de planos comunicativos en forma de cajas chinas, se hallan en toda la novela. A pesar de las dificultades relacionadas con esta estructura novelesca, la trama se desarrolla cronologicamente, lo cual evita la ruptura total de la comunicación entre el autor implícito y el lector implícito.

"Lo esencial es que no se sabe observado" (11)

Los resultados hacen necesario ahora volver sobre el análisis de la situación narrativa de la escena introductoria. Gracias al dispositivo en el suelo del apartamento de Terencio y Donají, el protagonista puede obscriar las actividades de Yin y Sarro en cada una de sus habitaciones. Este hecho vuelve comprensible la libertad casi ilimitada de movimiento del narrador, así como su capacidad de reproducir diálogos palabra por palabra. La explicación y descripción de acontecimientos, el empleo especial del tiempo del presente, así como el carácter ejemplar de la escena, admiten la suposicion de que se trata de una carta que escribe el protagonista mientras está observando los hechos que ocurren en el apartamento de abajo.

Esta suposición queda comprobada con las ilustraciones que acompañan el texto de la segunda edición y las cuales facilitan al lector la comprensión de la novela. Si bien el empleo de este recurso ayuda en la reconstrucción de la organización narrativa de determinadas secuencias de la trama, aun así la complejidad de la estructura narrativa no desmerece en nada ante la version original.

Para elucidar estas complejidades, el método del análisis comunicativo sobre la base del planteamiento de Jaap Lintvelt ha resultado provechoso. 


\section{BIBLIOGRAFÍA CITADA}

Bưnler, Karl. Sprachtheorie. Die Darstellungsfuntion der Sprache. Jena: Fischer, 1934.

Burunat, Silvia. El monólogo interior como forma narrativa en la novela española (1940-1975). Madrid: José Porrúa Turanzas, 1980.

Generte, Gerard. "Discours du récil: essai de méthode." Figures III. París: Seuil, 1972. 67-286.

Greimas, Algirdas Julien y Courtés, J. Semiótica. Diccionario razonado de la leoría del lenguaje. Biblioteca Románica Hispánica 5. Madrid: Gredos 1982.

Joyce, James. Ulysses. The Corrected Text. Harmondsworth: Penguin Books Ltd., 1987.

Lintvelt, JaAp. Essai de typologie narrative. Le "point de vue". Théorie et analy'se. París: José Corti, 1981.

NeUHAus, Volker. Typen multiperspektivischen Erzählens. Köln: Böhlau Verlag, 1971.

Sainz, Gustavo. Gazapo. $4^{a}$ ed. Serie del volador. México: Joaquín Mortiz, 1967.

- - Obsesivos días circulares. Colección Novelistas Contemporáneos. México: Joaquín Mortiz, 1969.

- - Obsesivos días circulares. Nueva versión con un epílogo de David Decker. México: Grijalbo, 1979.

Schmo, Wolf. Der Texiaufbau in den Erzählungen Dostoevskijs. Beihefte zur Poetica 10 (1973).

Zenke, Jurgen. Die deutsche Monologerzählung im 20. Jahrhundert. Kölner Germanistische Studien 12. Köln/Wien: Böhlau Verlag, 1976. 